\title{
ANÁLISE DA VIABILIDADE ECONÔMICA E FINANCEIRA PARA IMPLANTAÇÃO DE UMA INDÚSTRIA DE CONFECÇÕES NO MUNICÍPIO DE VISTA GAÚCHA - RS
}

\section{ANALYSISECONOMIC AND FINANCIAL VIABILITY TO IMPLEMENT A CLOTHING INDUSTRY IN VISTA GAÚCHA - RS MUNICIPALITY}

\author{
Camila Freitas Sant'Ana \\ Universidade Regional de Blumenau - FURB - Blumenau - Brasil \\ camila-fsantana@hotmail.com
}

\begin{abstract}
Resumo
O objetivo deste estudo é analisar a viabilidade econômica e financeira para a implantação de uma indústria de confecções no município de Vista Gaúcha - RS. A pesquisa caracteriza-se como exploratória, quantitativa e estudo de caso. A amostra da pesquisa somou-se em 106 empresas do comércio varejista de confecções dos municípios de Palmitinho - RS, Tenente Portela - RS, Três Passos - RS e Vista Gaúcha-RS. Assim, realizou-se uma pesquisa de mercado na região noroeste do Rio Grande do Sul, bem como foi elaborado um levantamento de orçamentos necessários para projeções dos demonstrativos econômico-financeiros e dos instrumentos de análise de investimentos. Os resultados do estudo demonstraram a viabilidade do projeto, considerando os regimes tributários do país, do qual evidenciou-se que o regime mais vantajoso econômico e financeiramente seria o regime tributário do simples nacional, como aproximadamente retorno do investimento total de $R \$ 79.578,00$ no período de 6 meses após início das atividades operacionais da indústria de confecções.
\end{abstract}

Palavras-chave: plano de negócio; viabilidade econômico-financeira; projeção de investimento.

\section{Introdução}

No Brasil a economia é movimentada pelo Produto Interno Bruto - PIB, que refere-se aos bens e serviços produzidos no país, neste contexto o sistema de informação InfoMoney (2007), aponta que o conhecimento dos fatores influentes no processo de desenvolvimento faz com que novas oportunidades de exploração apareçam no mercado nacional. Entretanto estabelece-se a necessidade do desencadeamento do espírito empreendedor para buscar cada vez mais o desenvolvimento do meio econômico e social regional. De acordo com o Serviço Brasileiro de Apoio às Micro e Pequenas Empresas [SEBRAE] (2004), o mundo dos negócios demanda de uma 
série de fatores para se obter o sucesso empresarial, assim destacam habilidades gerenciais, um bom conhecimento do mercado, capacidade empreendedora e conhecimentos em logística operacional.

Deste modo, a implantação de qualquer empreendimento necessita de uma série de processos de análise e avaliação das áreas que busca abranger no mercado. E sob este aspecto Gray e Johnston (1977), salientam que os administradores precisam definir a eficiência operacional para que se chegue ao resultado desejado para o negócio, sendo que um dos principais fatores almejados é a lucratividade.

Com base em dados pesquisados referente ao ano de 2010 pelo SEBRAE (2011), os mesmos apontam que na realidade empresarial brasileira boa parte dos empresários que entram na atividade levam suas empresas a falência, devido à falta de prática dos fatores citados anteriormente, do qual destaca-se em primeiro lugar a falta de capital de giro, posterior a falta de clientes, problemas financeiros, entre outros, mas sem deixar de comentar que a carga tributária elevada fixou-se na décima terceira posição, demonstrando ao contrário do que muitos pensam, ela não é a principal vilã responsável pelo fechamento das $58 \%$ das empresas de pequeno e médio porte que não chegam a completar cinco anos de atividade no mercado.

Partindo deste pressuposto, a Fundação Getúlio Vargas [FGV] (2010), comenta que todo projeto empresarial deve ser estudado com enfoque na análise de viabilidade econômico-financeira dos projetos de investimento em determinada atividade, pois é de suma importância para a tomada de decisão nas empresas antes de se iniciar as atividades, para verificar se existe atratividade e oportunidade de negócio, de modo que consegue-se ter uma claridade sobre o retorno do investimento através da realização deste tipo de levantamento.

Embora, sob aspecto de avaliação dos setores que movimentam a economia, a respeito do Brasil dentro do cenário de confecções no mercado externo e interno, o país caracteriza-se principalmente como um "produtor/consumidor", pelo fato que grande parte da produção destina-se para o mercado interno. Ainda de acordo com dados levantados pelo Banco Nacional do Desenvolvimento Econômico e Social - BNDES, e pela Associação Brasileira da Indústria Têxtil e de Confecções - ABIT (2011), estima-se um crescimento para os próximos 5 (cinco) anos, alcance cerca de U\$\$ 856 bilhões para o ano de 2014.

Assim a questão problema de pesquisa é: existe viabilidade econômica e financeira para a implantação de uma indústria de confecções no município de Vista Gaúcha - RS? Deste modo, o objetivo é analisar a viabilidade econômica e financeira para a implantação de uma indústria de confecções no município de Vista Gaúcha - RS.

Com base na ABIT (2011) o desenvolvimento de um estudo de viabilidade econômicofinanceiro do setor de vestuário é muito importante, pois o ramo de vestuário do segmento de roupas casuais tem por meta atender os desejos e necessidades dos consumidores que buscam cada 
vez mais nos produtos as características como qualidade, preço, marca, modelo, etc. De modo que planos de negócios contribuem para identificar a viabilidade do empreendimento, auxiliando no processo de tomada de decisão de futuros empresários e investidores, por meio das informações sobre os possíveis gastos decorrentes do projeto, das condições e da capacidade do mercado para que seja mais próximo de se atingir o sucesso da organização por meio do uso do planejamento empresarial. Outra contribuição, refere-se quanto a necessidade de avaliar se o negócio será competitivo no mercado, bem como identificação dos riscos e das oportunidades de crescimento no cenário econômico inserido (SEBRAE, 2004).

\section{Referencial Teórico}

Nesta seção apresenta-se o referencial teórico pertinente ao tema da pesquisa, abordando os custos e métodos de custeio, instrumentos de análise dos investimentos e características dos regimes tributários.

\subsection{Custos e instrumentos de análise dos investimentos}

A contabilidade presta apoio as decisões de planejamento, de organização, coordenação e controle dos processos através do fornecimento de informações para administradores, credores e outros envolvidos, ela possibilita que a empresa seja competitiva dentro do cenário comercial que atua, através do melhor desempenho gerencial contábil do orçamento e da gestão estratégica (Padoveze, 2009).

De acordo com Leone (2009), a contabilidade de custos é a base que recebe ou evidência os dados de modo organizado, sob o qual gera as informações monetárias e não monetárias, internas e externas que serão analisadas e interpretadas pela gestão gerencial da empresa, a fim de atingir os objetivos, metas e os parâmetros para a planejamento do orçamento da organização.

Para Abreu e Carneiro (2012), o uso das metodologias dispostas pela contabilidade de custos auxilia no gerenciamento de projetos, bem como contribui para que os profissionais possam desenvolver com maior eficiência e eficácia a execução das atividades demandadas pelo projeto.

Assim, a contabilidade de custoscorrobora na identificação dos custos fixos e variáveis da atividade operacional, sendo os custos fixos aqueles utilizados especificamente a produção sem aumentar de volume, ou seja, é o custo constante da atividade de modo que independem da quantidade de produção (Backer \& Jacobsen, 1977). Já os custos variáveis, também conhecidos como custos marginais, são aqueles que estão diretamente ligados a produção, caracterizados pelo crescimento constante em relação ao volume de vendas (Santos, 2005).

Em se tratando de métodos de custeio para o setor industrial, têm-se como melhor indicação para utilização o método do custeio por absorção, também conhecido como custeio integral, que 
tem por objetivo custear o produto de acordo com os custos fixos e variáveis, apropriados da forma direta ou indireta, avaliados pelos critérios de rateio (Crepaldi, 1999).

Estudos analisaram o uso do custeio por absorção em diferentes casos industriais, como o estudo de Coronetti, Beuren e Sousa (2012) que verificaram quais são os métodos de custeio mais utilizados na indústria do estado de Santa Catarina, do qual evidenciaram que o custeio por absorção aparece como o sistema de custeio mais usado nas indústrias dentre o conjunto de outros métodos de custeio. Já o estudo de Severiano Filho e Melo (2009), destaca que o mesmo possui algumas limitações, mas que são superadas devido a sua operacionalidade que propicia um gerenciamento mais eficaz na determinação e dos custos unitários e na decisão de fixação dos preços para composição dos orçamentos.

Deste modo, as principais características do custeio por absorção, conforme Padoveze (2009) é avaliar os custos diretos e indiretos industriais por meio da utilização de critérios de rateio ou apropriação, sem considerar os gastos relacionados dos processos administrativos e comerciais, do qual resulta-se no custo dos produtos e de serviços vendidos no período, que podem ser mensurados na demonstração do resultado do exercício e na avaliação dos estoques finais e nos estoques em elaboração industriais. Para Leone (2009, p. 242) este método propõe que os custos diretos e indiretos da produção sejam absorvidos de acordo com sua proporção de participação em cada produto ou serviço.

Os custos a serem avaliados apresentam diferentes distinções, visto que são caracterizados em pagamento ou desembolso, os gastos, os custos, despesas, perdas e investimentos (Martins, 2000). Quanto ao pagamento ou desembolso, este refere-se ao momento da saída de dinheiro da empresa, resultante do pagamento da aquisição de um bem ou serviço, do qual o desembolso possa ter ocorrido anteriormente, no momento ou após a entrada do bem ou serviço adquirido (Pinto, Limeira, Silva \& Coelho, 2008).

Já os gastos de acordo com Martins (2000) representam os sacrifícios financeiros na produção de outros bens e serviços. Em relação as despesas, Pinto et al., (2008, p. 20), abordam como "gastos com bens e serviços consumidos direta ou indiretamente com a finalidade de obtenção de receitas". Quanto a perda Martins (2000) discorre que é quando um bem ou serviço são consumidos por meio de uma anormalidade ou involuntariedade, como incêndios, inundações, etc. Tratando-se do investimento, Pinto et al., (2008, p. 19) conceituam como o "gasto com bem ou serviço ativado em função de sua vida útil ou de benefícios atribuíveis a períodos futuros".

Os custos dos produtos estão relacionados ao processo de produção/fabricação de bens para o consumo, de modo que todos os gastos incorridos nesta fase operacional são incluídos como custos e somente após o produto pronto para a venda os demais custos evidenciados serão contabilizados como despesa (Martins, 2000). Ainda quanto a mensuração dos custos, o método 
mais utilizado e permitido perante a legislação tributária é o método da média ponderada, que com base em Crepaldi (1999), consiste no cálculo dos custos dos produtos a cada nova entrada em estoque, que aplica-se a soma e divisão pelo montante final, onde o resultado obtido compreende ao custo médio para cada unidade disponível na conta estoque.

Do qual passa-se a contabilidade gerencial que contribui na confrontação e verificação das técnicas e procedimentos contábeis aplicados pela contabilidade tributária, contabilidade de custos, contabilidade de análises financeiras e de balanços, voltada a prover administração da empresa de informações relevantes para o processo de tomadas de decisão da gestão empresarial e bem como avaliar a eficiência e a eficácia organizacional (Iudícibus, 1998).

Ainda corrobora nos procedimentos de realização das análises do investimento por meio do estudo dos fluxos de caixa, evidenciados pela Demonstração do Fluxo de Caixa - DFC, que de acordo com Zdanowicz (2001) e Braga (2008), esta ferramenta gerencial auxilia o administrador financeiro a realizar seus trabalhos de planejamento, organização, coordenação, posicionamento e controle dos recursos econômicos e financeiros do negócio ao que deve ser avaliado por meio da utilização de técnicas e métodos capazes de mensurar ao longo de um período de tempo determinado o valor atual líquido e a taxa interna de retorno.

$\mathrm{Na}$ sequência faz-se indispensável examinar o prazo de retorno do investimento, que é avaliado pelo emprego do método payback, que destinado a determinar o tempo hábil que espera-se que o investimento seja recuperado (Bruni \& Famá, 2007), do qual Braga (2008) relata que quanto maior o período de tempo maior será o grau de incerteza nas previsões e o risco do negócio. Entretanto Leite (1994) discorre sobre críticas pertinentes ao payback, sendo a discussão em torno que este método não atualizava o valor do dinheiro no tempo, inversamente o que o método de avaliação do valor presente líquido objetiva mensurar, que é a diferença entre o valor monetário presente das entradas e saídas, em aspecto a taxa de desconto levantadas.

Em se tratando da técnica da taxa interna de retorno - TIR, para Braga (2008, p. 292) referese a "taxa de rentabilidade periódica equivalente de um investimento. Geralmente, a TIR é definida para períodos anuais". Portanto, a taxa interna de retorno é uma taxa de desconto que igualar-se o valor presente das entradas e dos desembolsos líquidos do investimento.

\subsection{Regimes tributário das pessoas jurídicas}

A elaboração de um planejamento tributário é fundamental para verificar qual é regime de apuração que a empresa se enquadra e que proporcionará maior proveito legal para a organização. Assim sendo, Fabretti (2005) condiz que o planejamento tributário é um estudo realizado preventivamente sobre os efeitos jurídicos e econômicos, de modo que o mesmo exige 
conhecimento e bom senso do planejador, determinado como ferramenta importantíssima para a contabilidade em todas as suas formas.

Visto que o imposto de acordo com o Código Tributário Nacional [CTN] (2012), Art. 16. trata-se do "tributo cuja obrigação tem por fato gerador uma situação independentemente de qualquer atividade estatal específica, relativa ao contribuinte", que é calculado conforme a modalidade de tributação que a empresa está adequada. Sendo que o fato gerador dos impostos pode ocorrer por meio da aquisição ou venda de bens, valores e títulos, passíveis de numerários correspondentes as disponibilidades e os proventos de qualquer natureza, observados mediantes leis, normas e decretos que versem sobre o assunto (CTN, 2012).

Os impostos incidentes na atividade operacional são o imposto de renda da pessoa jurídica IRPJ, o imposto sobre produtos industrializados -IPI, o imposto sobre circulação de mercadorias e serviços - ICMS, a contribuição ao programa de integração social - PIS, e a contribuição para o fundo de investimento social - COFINS, que apresentam cada um respectivamente alíquota de tributação para se apurar seu saldo, dependente do regime tributário que pode ser lucro real, lucro presumido ou simples nacional (Fabretti, 2005).

O Decreto 3000 de 26 de março de 1999, dispõe sobre as modalidades existentes de tributação dos resultados das pessoas jurídicas, sendo eles: o lucro real trimestral e anual, o lucro presumido e o simples nacional. De acordo com Oliveira, Chieregato, Perez e Gomes (2004, p. 176) o lucro real é definido por como sendo:

Olucro líquido do período apurado na escrituração comercial, denominado lucro contábil, ajustado pelas adições, exclusões e compensações autorizadas pela legislação do Imposto de Renda. Os ajustes do lucro líquido do período de apuração e a demonstração da apuração do lucro real devem ser transcritos no Livro de Apuração do Lucro Real (LALUR).

Já no que tange o lucro presumido, o mesmo é uma alternativa menos complexa para as pessoas jurídicas desobrigadas a apuração pelo lucro real, que é realizada por uma forma menos burocrática dentro de algumas organizações. Com base na Lei n. 12.814, de maio de 2013, o caput do Art. 13, discorre qual é a característica fundamental exigida para que as empresas possam optar pela apuração pelo lucro presumido, sendo as pessoas jurídicas que:

Cuja receita bruta total no ano-calendário anterior tenha sido igual ou inferior a $\mathrm{R} \$$ 78.000.000,00 (setenta e oito milhões de reais) ou a $\mathrm{R} \$ 6.500 .000,00$ (seis milhões e quinhentos mil reais) multiplicado pelo número de meses de atividade do ano-calendário anterior, quando inferior a 12 (doze) meses, poderá optar pelo regime de tributação com base no lucro presumido.

Quanto a modalidade de tributação do simples nacional, o mesmo é regido pela Lei Complementar 123/2006, que dispõe sobre o conceito fundamental das microempresas ou empresas de pequeno porte elemento essencial para que este regime possa ser aderido pelas empresas, ou seja, 
as organizações empresariais precisam enquadrar-se no conceito de microempresa - ME ou como empresa de pequeno porte - EPP para serem tributadas por este regime especial e simplificado de tributação.

\section{Procedimentos Metodológicos}

Com base nos objetivos apresentados pelo trabalho, a pesquisa se caracteriza como exploratória, quantitativa e estudo de caso. Em relação aos objetivos a pesquisa caracteriza-se como exploratória, que busca apenas "levantar informações sobre um determinado objeto, delimitando assim um campo de trabalho, mapeando as condições de manifestação desse objeto" (Severino, 2007, p. 123). Quanto a abordagem do problema da pesquisa, a mesma é tratada de forma quantitativa, porque permitiu à quantificação, análise e interpretação dos dados obtidos por intermédio da pesquisa (Gil,1999). A pesquisa caracteriza-se de acordo com a apresentação dos dados como um estudo de caso, pois refere-se a um levantamento com maior profundidade de determinado assunto ou tema (Cervo \& Bervian, 1996).

A população da pesquisa compreende a todas as empresas do comércio varejista específico de confecções de vestuário dos municípios de Palmitinho - RS, Tenente Portela - RS, Três Passos RS e Vista Gaúcha - RS que foram identificados por intermédio de relatório disponibilizado pelo setor de indústria e comércio de cada cidade. A Tabela 01, apresenta detalhadamente a representatividade da população e amostra do estudo.

Tabela 1 - Representatividade da População e amostra

\begin{tabular}{ccc}
\hline Município & População & Amostra \\
\hline Palmitinho -RS & 23 & 20 \\
Tenente Portela - RS & 42 & 33 \\
Três Passos - RS & 63 & 45 \\
Vista Gaúcha - RS & 8 & 8 \\
\hline Total & $\mathbf{1 3 6}$ & $\mathbf{1 0 6}$ \\
\hline
\end{tabular}

Fonte: Dados da pesquisa.

A amostra foi determinada com base em Barbetta (2008), considerando um erro amostral equivalente a $8 \%$ sobre a população da pesquisa e a amostragem resultou em 106 empresas. A coleta dos dados foi realizada mediante aplicação de questionário in loco, com visita ao estabelecimento comercial, por meio de aplicação do questionário online e via telefone. As questões da pesquisa de mercado foram formuladas para obter informações sobre as características dos produtos, preço de custo dos clientes, a aceitação do projeto e quantidade que poderia ser adquirida pelo projeto, a quantidade mensal vendida no comércio e as formas de pagamento. A coleta dos orçamentos foi realizada via telefone e solicitação do orçamento via e-mail, junto das lojas especializadas na região abordada. 
A pesquisa de mercado foi desenvolvida durante o período do mês de maio a setembro do ano de 2013 e a solicitação dos orçamentos junto aos representantes comerciais ocorreu no mês de agosto de 2013. Após foram desenvolvidos a análise, tabulação e interpretação dos dados.

\section{Análise e Interpretação dos Dados}

Este tópico aborda a análise dos dados a fim de atingir o objetivo proposto pelo estudo de analisar a viabilidade econômica e financeira para a implantação de uma indústria de confecções no município de Vista Gaúcha - RS.

Em relação aos informações levantadas pela pesquisa de mercado, questionou se os lojistas realizavam compras de peças de vestuário de uma indústria sem marca renomada no mercado, se estas empresas estariam dispostas a comprar os produtos de uma indústria de vestuário localizada no município de Vista Gaúcha - RS, a aceitação do projeto, o tipo de segmento de vestuário que a loja mais vende atualmente, o principal gênero dos consumidores e a média de camisas e camisetas que são comercializadas por mês no estabelecimento. Os resultados obtidos estão apresentados sinteticamente na Tabela 2.

Tabela 2 - Análise da demanda mercadológica

\begin{tabular}{cc}
\hline Descrição & Resultado médio obtido \\
\hline Venda de roupas sem marca famosa & Sim c/ $79 \%$ \\
Aceitação do projeto & Sim c/ $89 \%$ \\
Segmento mais comercializado & Adulto c/ $71 \%$ \\
Gênero do público alvo & Feminino c/ $88 \%$ \\
Quantidade de demanda do projeto & 4.071 unidades \\
Principais fatores influentes & Preço e Qualidade \\
Preço médio pago pelos clientes & R $\$ 23,34$ \\
Forma de pagamento dos clientes & Parc. em 30 dias -1 vez c/ $46,7 \%$ \\
\hline
\end{tabular}

Fonte: Dados da pesquisa.

A Tabela 2 demonstra que as empresas vendem roupas que não são de marcas consagradas no mercado, mostrando abertura no mercado para o negócio mais bem representado pela aceitação do projeto, destacando que o segmento de camisas e camisetas mais comercializado é do segmento de roupas adultas do gênero feminino.

Em relação à questão que aborda verificar se as empresas estão dispostas a comprar os produtos de uma indústria de confecções de vestuário localizada no município de Vista Gaúcha apresentado na Tabela 2, foi abordado se as empresas do comércio varejista de confecções trabalham com algum tipo de taxa, ou seja, cheque caução para garantir a efetivação do negócio e o resultado obtido foi que $100 \%$ das empresas não utilizam a prática de taxas de garantia para a efetivação das compras, na modalidade arras ou sinal de negócio prevista pelo Código Civil (2002). 
Verificado que para atender a demanda por camisas e camisetas adultas para adultos do gênero feminino na Tabela 2, que segundo os comerciantes é o público feminino que mais realiza compras de vestuário, os dados relacionados a quantidade de produtos vendidos pelas empresas pesquisadas permitiram evidenciar a quantidade de unidades que as mesmas estão dispostas a negociar com este projeto que foi de $36,3 \%$ da demanda e o restante de $63,7 \%$ da demanda ficaria no mercado dos concorrentes. No entanto em relação aos dados apresentados, faz-se necessário destacar que 3 respondentes de toda a amostra alvo decidiram não comentar sobre a demanda total de sua loja e 6 empresas decidiram não comentar sobre a possível quantidade que poderia ser comprada da indústria estudada por este projeto.

Quanto a pesquisa realizada junto aos fornecedores de máquinas e equipamentos, há disponibilidade de revendedores especializados com serviços de assistência técnica na região, do qual o prazo médio de entrega dos pedidos varia entre 7 a 10 dias úteis caso não disporem em estoque, com possibilidades de parcelamento para o cliente.

Abordando os fornecedores de matéria-prima, os orçamentos foram buscados junto a uma empresa de atacado localizada na região, que dispõe de uma variada linha de tecidos e aviamentos, que também pratica vendas parceladas. No entanto, existe outros fornecedores de matéria-prima que realizam distribuição direta para as indústrias e a disponibilidade de pedidos on-line via internet nos sites das empresas têxteis e atacadistas.

Ainda assim, compreende-se que para a concretização de um projeto empresarial é necessário se realizar um planejamento de todos os recursos que serão desembolsados para o negócio, assim para cálculo do investimento inicial e de todos as demais previsões, uma ressalva importante para este estudo é que o projeto dispõe de dois sócios com conhecimento técnico na área operacional de vestuários e outro sócio especializando-se em pós-graduação na área de contabilidade e controladoria.

Deste modo, tem-se na Tabela 3 a apresentação do investimento total inicial no projeto, com capacidade para realizar as atividades operacionais propostas de acordo com as especificações da indústria de confecções.

Tabela 3 - Investimento total inicial

\begin{tabular}{ccc}
\hline Investimento fixo & \multicolumn{2}{c}{ Valor R\$ } \\
\hline Máquinas e equipamentos & $\mathrm{R} \$$ & $22.546,80$ \\
Móveis e utensílios & $\mathrm{R} \$$ & $7.900,00$ \\
Veículo & $\mathrm{R} \$$ & $18.000,00$ \\
Matéria Prima Total & $\mathrm{R} \$$ & $26.991,20$ \\
Subtotal (invest. fixo) & $\mathrm{R} \$$ & $75.438,00$ \\
Capital Inicial Caixa & $\mathrm{R} \$$ & $4.140,00$ \\
\hline Total & $\mathbf{R} \$$ & $\mathbf{7 9 . 5 7 8 , 0 0}$ \\
\hline
\end{tabular}

Fonte: Dados da pesquisa. 
O valor constante na Tabela 3, não considera no investimento inicial o valor do galpão que será cedido pelos sócios, de modo que o aluguel do mesmo será alocado mediante valor econômico na Demonstração do Resultado do Exercício - DRE. Já em relação ao capital inicial, este corresponde a estimação de despesas antes de começar a movimentar receitas, incluindo a legalização da indústria que já se possui CNPJ registrado porém necessita de um processo de transformação de empresa e demais registros em associações e sindicatos das indústrias de confecções do Rio Grande do Sul.

Todo os orçamentos levantados com auxílio das empresas fornecedores e clientes do mercado que colaboraram na evidenciação dos dados que resultaram no valor total do investimento no projeto de $\mathrm{R} \$ 79.578,00$. Deste valor total do investimento, calculou-se integralização dos sócios no valor de $\mathrm{R} \$ 30.000,00$ para o capital social do projeto, destinado principalmente para a compra do veículo usado orçado com base na Fundação Instituto de Pesquisas Econômicas, que não pode ser financiado pelos projetos do Banco Nacional do Desenvolvimento Econômico e Social BNDES pela linha de crédito do FINAME e pelo Banco do Brasil por intermédio do PROGER.

O valor resultante de $\mathrm{R} \$ 49.578,00$ foi simulado por meio de duas linhas de crédito, do qual para a aquisição de máquinas e equipamentos via FINAME no valor projetado de financiamento foi de $\mathrm{R} \$ 20.292,12$, que acrescido das despesas financeira o valor total ficou em $\mathrm{R} \$ 27.409,73$ para pagamento no prazo de 60 meses. O restante dos créditos de 29.285,88 foram simulados por meio da linha de crédito do PROGER respectivamente no prazo de 60 meses para amortização total do valor de $\mathrm{R} \$ 36.977,25$, assim somando as despesas financeiras de ambos o valor mensal foi de $\mathrm{R} \$$ 246,82 .

Quanto a projeção das despesas operacionais considerou-se na apuração, todos os gastos, desembolsos e despesas administrativas, com vendas e as despesas financeiras decorrentes dos financiamentos, das despesas tributárias do projeto, sendo que para determinação das depreciações foram utilizadas para estimação da vida útil dos bens sob fins gerenciais o estudo do Instituto Brasileiro de Avaliações e Perícias de Engenharia de São Paulo [IBAPE] (2013). Em relação aos custos fixos mensais, a projeção dos mesmos está apresentada na Tabela 4.

Tabela 4 - Custos Fixos Mensal

\begin{tabular}{cccc}
\hline Descrição & Valor Total pelo Simples & Valor Total reg. Normal & Valor p/ fins de IRPJ/CSLL \\
\hline Depreciação & $\mathrm{R} \$ 210,01$ & $\mathrm{R} \$ 210,01$ & $\mathrm{R} \$ 375,78$ \\
Aluguel cedido & $\mathrm{R} \$ 678,00$ & $\mathrm{R} \$ 678,00$ & $\mathrm{R} \$ 678,00$ \\
Pró-labore & $\mathrm{R} \$ 1.500,00$ & $\mathrm{R} \$ 1.800$ & $\mathrm{R} \$ 1.800$ \\
Prov. de manutenção & $\mathrm{R} \$ 71,78$ & $\mathrm{R} \$ 71,78$ & $\mathrm{R} \$ 71,78$ \\
Equip. de segurança & $\mathrm{R} \$ 62,15$ & $\mathrm{R} \$ 62,15$ & $\mathrm{R} \$ 62,15$ \\
Despesas fixas adm. & $\mathrm{R} \$ 1.827,36$ & $\mathrm{R} \$ 2.127,36$ & $\mathrm{R} \$ 2.118,65$ \\
Despesas fixas vendas & $\mathrm{R} \$ 2.062,39$ & $\mathrm{R} \$ 2.362,39$ & $\mathrm{R} \$ 2.436,67$ \\
Despesas financeiras & $\mathrm{R} \$ 246,82$ & $\mathrm{R} \$ 246,82$ & $\mathrm{R} \$ 662,67$ \\
\hline Total & $\mathbf{R} \$ \mathbf{6 . 6 5 7 , 7 0}$ & $\mathbf{R} \$ \mathbf{7 . 5 5 7 , 7 0}$ & $\mathbf{R} \$ \mathbf{8 . 2 0 5 , 7 0}$
\end{tabular}

Fonte: Dados da pesquisa. 
Nesta Tabela 4 é apresentado a soma dos custos fixos operacionais mensais para a produção das duas linhas de produtos, composto pela soma das despesas administrativas, mais as despesas com vendas, mais o orçamento de manutenção das máquinas e equipamentos, mais os equipamentos de proteção e segurança, bem como as depreciações mensais das máquinas e equipamentos operacionais, mais os valores da depreciação das cadeiras, escrivaninha, bebedor e rádio, acrescidos do valor do aluguel simbólico, ou seja, econômico do galpão de $90 \mathrm{~m}^{2}$, todos mensurados para fins gerenciais e também devidamente calculados com base na regra de depreciação estipulado pela RFB para fins de IRPJ e CSLL. Deste valor cabe salientar que o total não inclui a soma dos custos fixos com mão de obra.

Assim, considerando estas informações das despesas administrativas, das despesas com vendas, das despesas operacionais, mais a soma da média das despesas financeira, têm-se uma porcentagem representativa das despesas de $10,65 \%$ sobre as vendas pelo simples nacional, 12,27\% sobre as vendas para o lucro presumido e 13,3\% sobre as vendas para o lucro real.

Quanto aos custos relacionados a contratação de 5 funcionários para atingir a capacidade produtiva de 2.640 unidades de produtos mensais, divididos em camisetas e camisas, cerca de 64,85\% da demanda, a Tabela 5 apresenta a síntese do dos custos com a mão de obra.

Tabela 5 - Apresentações dos custos com funcionários

\begin{tabular}{|c|c|c|c|c|c|}
\hline \multicolumn{3}{|c|}{ Simples Nacional } & \multicolumn{3}{|c|}{ Regimes Normais } \\
\hline Descrição & Valor Unit. & Valor Total & Descrição & Unit & Valor Total \\
\hline $\begin{array}{l}\text { Despesas c/ } \\
\text { Salários } \\
\text { Desp. c/ FGTS }\end{array}$ & $\mathrm{R} \$ 739,20$ & $\mathrm{R} \$ 3.696,00$ & Despesas Com Salários & $\mathrm{R} \$ 739,20$ & $\mathrm{R} \$ 3.696,00$ \\
\hline $8 \%$ & $\mathrm{R} \$ 59,14$ & $\mathrm{R} \$ 295,68$ & Desp. FGTS 8\% & $\mathrm{R} \$ 59,14$ & $\mathrm{R} \$ 295,68$ \\
\hline $\begin{array}{l}\text { Desp. c/ Férias } \\
\text { Mensal }\end{array}$ & $\mathrm{R} \$ 77,03$ & $\mathrm{R} \$ 385,16$ & $\begin{array}{l}\text { Desp. INSS Patronal } 20 \% \text { + Rat } 3 \% \\
\text { + Outras Entidades 5,80\% + Fap } 2\end{array}$ & $\mathrm{R} \$ 235,07$ & $\mathrm{R} \$ 1.175,33$ \\
\hline $\begin{array}{l}\text { Desp. c/ FGTS } \\
\text { 8\% Férias } \\
\text { Mensal } \\
\text { Desp. c/ } 13^{\circ}\end{array}$ & $\mathrm{R} \$ 6,16$ & $\mathrm{R} \$ 30,81$ & Des. C/ Férias Mensal & $\mathrm{R} \$ 77,03$ & $\mathrm{R} \$ 385,16$ \\
\hline Salário & $\mathrm{R} \$ 56,50$ & $\mathrm{R} \$ 282,50$ & $\begin{array}{c}\text { Desp. C/ FGTS 8\% Férias Mensal } \\
\text { Desp. INSS Patronal 20\% Férias }\end{array}$ & $\mathrm{R} \$ 6,16$ & $\mathrm{R} \$ 30,81$ \\
\hline $\begin{array}{c}\text { Despesa FGTS } \\
13^{\circ}\end{array}$ & $\mathrm{R} \$ 4,52$ & $\mathrm{R} \$ 22,60$ & $\begin{array}{c}\text { Mensal + Rat } 3 \%+\text { Outras Entidades } \\
5,80 \%+\text { Fap } 2 \\
\text { Despesa FGTS } 13^{\circ}\end{array}$ & $\begin{array}{l}\mathrm{R} \$ 24,50 \\
\mathrm{R} \$ 4,52\end{array}$ & $\begin{array}{l}\mathrm{R} \$ 122,48 \\
\mathrm{R} \$ 22,60\end{array}$ \\
\hline & & & $\begin{array}{c}\text { Desp./ } 13^{\circ} \text { Salário } \\
\text { Desp. INSS Patronal } 13^{\circ}+\text { Rat } 3 \%+ \\
\text { Outras Entidades } 5,80 \%+\text { Fap } 2 \\
\end{array}$ & $\begin{array}{l}\mathrm{R} \$ 56,50 \\
\mathrm{R} \$ 17,97 \\
\end{array}$ & $\begin{array}{l}\mathrm{R} \$ 282,50 \\
\mathrm{R} \$ 89,84 \\
\end{array}$ \\
\hline Total & R\$ 942,55 & $R \$ 4.712,75$ & & R\$ 1.220,08 & R\$ 6.100,39 \\
\hline
\end{tabular}

Fonte: Dados da pesquisa.

Os salários bases apresentados na Tabela 5, foram calculados conforme a convenção coletiva de trabalho 2013/2014, firmada pelo Sindicato das Indústrias de Vestuário do Rio Grande 
do Sul [SIVERGS] (2013). Nota-se que pelo regime simples nacional, o custo com os funcionários é inferior ao dos regimes normais, devido que este regime simplificado não prevê-se a arrecadação do INSS patronal e dos demais percentuais correspondentes as entidades sociais, bem como é zerado o índice e alíquotas do Fator Acidentário de Prevenção - FAP e do Risco de Acidente no Trabalho - RAT, que de acordo com o Código Nacional de Atividade Econômica - CNAE e as normas vigentes da Receita Federal Brasileira [RFB] este projeto pode aderir tanto no regime tributário do simples nacional, lucro presumido ou lucro real a ser utilizado no exercício financeiro.

As despesas com pró-labores dos sócios também apresentam peculiaridades, considerando o valor do pró-labore de $\mathrm{R} \$ 1.500,00$ o custo total apurado com base no simples nacional para os três sócios é de $\mathrm{R} \$ 4.500,00$, já para os regimes normais o valor total resulta em $\mathrm{R} \$ 5.400,00$ mensais, sendo mais vantajoso a opção pelo regime do simples nacional.

Para base dos cálculos dos custos fixos operacionais de fabricação dos produtos industriais, considerou-se as premissas de 8 horas diárias de trabalho multiplicado pela média de 22 dias úteis mensais, que resultou em 176 horas já descontados os descansos semanais dos funcionários e a média da capacidade produzida em peças por dia foi determinada em 120 unidades, que multiplicada pela média de dias mensais resulta na capacidade produtiva de 2640 unidades. Deste modo, a Tabela 6 apresenta o rateio da mão de obra.

Tabela 6 - Rateio da Mão de Obra

\begin{tabular}{ccc}
\hline Descrição & Valor - Simpl. Nacional & Valor - Reg. Normais \\
\hline Custos c/sal. e encarg. & $\mathrm{R} \$ 4.712,75$ & $\mathrm{R} \$ 6.100,39$ \\
Valor da hora trabalhada & $\mathrm{R} \$ 26,78$ & $\mathrm{R} \$ 34,66$ \\
\hline Valor Total M. Obra Unit. & $\mathbf{R} \mathbf{1 , 7 9}$ & $\mathbf{R} \$ \mathbf{2 , 3 1}$
\end{tabular}

Fonte: Dados da pesquisa.

$\mathrm{Na}$ sequência do rateio são considerados os custos dos materiais necessários para a produção, com base em informações técnicas dos sócios e também considerando os dados orçamentos adquiridos juntos aos fornecedores das matérias-primas, para o volume da capacidade produtiva mensal de 2640 unidades estimada, sendo que quanto aos custos variáveis referem-se as etiquetas, embalagens, tecidos, bordado ou impresso, perdas de tecido e energia elétrica, mais os custos indiretos de fabricação composto pela mão de obra e pelos custos fixos, todos analisados por unidade conforme demonstrados pela Tabela 7.

Tabela 7 - Custos totais unitários dos produtos

\begin{tabular}{cccccccc}
\hline Regime De Tributação & \multicolumn{2}{c}{ Simples Nacional R\$ } & \multicolumn{2}{c}{ Lucro Presumido R\$ } & \multicolumn{3}{c}{ Lucro Real R\$ } \\
\hline & & & & & Camiseta & Camiseta \\
Descrição & Camiseta & Camisa & Camiseta & Camisa & Masc. & Fem. & Camisa \\
Custos Variáveis Unit. & 7,92 & 10,37 & 6,58 & 8,62 & 6,58 & 5,85 & 8,62 \\
Custos Fixos Unit. & 4,31 & 4,31 & 5,17 & 5,17 & 5,42 & 5,42 & 5,42 \\
\hline Totais & $\mathbf{1 2 , 2 2}$ & $\mathbf{1 4 , 6 8}$ & $\mathbf{1 1 , 7 5}$ & $\mathbf{1 3 , 7 9}$ & $\mathbf{1 2 , 0 0}$ & $\mathbf{1 1 , 2 7}$ & $\mathbf{1 4 , 0 3}$ \\
\hline
\end{tabular}

Fonte: Dados da pesquisa. 
De acordo com a Tabela 7 é importante ressaltar que simples nacional não dispõe de nenhuma possibilidade recuperação de impostos para este tipo de produto, já o lucro presumido, apresenta possibilidade de recuperação do Imposto sobre Operações Relativas à Circulação de Mercadorias e sobre Prestações de Serviços de Transporte Interestadual Intermunicipal e de Comunicação - ICMS, de $17 \%$ sobre o valor da matéria-prima consumidas na produção, para o regime do lucro real, além do ICMS existem diferenças relacionadas aos critérios fiscais estabelecidos por normativas especificas da RFB, como por exemplo a utilização da depreciação em caráter fiscal, bem como a incidência de alíquotas que correspondem ao Imposto sobre Produto Industrializado - IPI, ao Programa de Integração Social - PIS e a Contribuição para o Financiamento da Seguridade Social - COFINS, que podem ser encontradas através da conferência e relação da tabela NCM - Nomenclatura Comum do Mercosul, que destaca as caraterísticas dos produtos e serve de base para relação da tributação com a tabela TIPI - Tabela de Incidência do Impostos sobre Produtos Industrializado e da Tabela CST - Código de Situação Tributária, ambas disponíveis pela RFB (Receita Federal Brasileira, 2013).

Ainda relacionado na Tabela 7, devem ser observados no lucro real os códigos NCM correspondentes aos produtos, que para as camisas de malha de uso masculino, apresentam-se perante a TIPI com alíquota zero e CST 08, que representa sem incidência de contribuição para PIS e COFINS, para as camisetas femininas, por serem de material de algodão sofrem modificações, sendo que não há a incidência de alíquota para a TIPI mais o CST apresenta-se como 01, o que revela que existe uma operação tributável com alíquota básica, ou seja, aplica-se no caso do lucro real também no cálculo dos custos com o produto as compensações dos impostos de PIS e COFINS, com as alíquotas de 1,65\% e 7,6\% respectivamente (Receita Federal Brasileira, 2013).

Determinado a capacidade produtiva do empreendimento de 2640 unidades produtos, divididas em 1320 camisetas e 1320 camisas, e os custos de produção unitários a Tabela 8 mostra o orçamento de matéria-prima.

Tabela 8 - Orçamento de Matéria-Prima

\begin{tabular}{|c|c|c|c|c|c|c|}
\hline Descrição & $\begin{array}{l}\text { Unid. } \\
\text { Medida }\end{array}$ & $\begin{array}{c}\text { Quant. } \\
\text { Unit/Prod. }\end{array}$ & $\begin{array}{c}\text { Valor } \\
\text { Prod/Unit. }\end{array}$ & $\begin{array}{c}\text { Quant. } \\
\text { Produção }\end{array}$ & Valor Total R\$ & Quant. Matéria-prima Total \\
\hline Etiquetas & Unid. & 3 & $\mathrm{R} \$ 0,04$ & 2640 & $\mathrm{R} \$ 108,24$ & 7920,00 \\
\hline $\begin{array}{l}\text { Embalagens } \\
\text { Tec. Pv-Malha }\end{array}$ & Unid. & 1 & $\mathrm{R} \$ 0,04$ & 2640 & $\mathrm{R} \$ 105,60$ & 2640,00 \\
\hline $\begin{array}{l}\text { Algodão e Linhas } \\
\text { Perdas Tec. Pv- }\end{array}$ & $\mathrm{Kg}$ & 0,324 & $\mathrm{R} \$ 6,77$ & 1320 & $\mathrm{R} \$ 8.938,51$ & 427,68 \\
\hline Malha Algodão & $\mathrm{Kg}$ & 0,028 & $\mathrm{R} \$ 0,59$ & 1320 & $\mathrm{R} \$ 774,61$ & 37,06 \\
\hline $\begin{array}{l}\text { Bordado/Impresso } \\
\text { Tecidos Tricoline }\end{array}$ & Peça & 1 & $\mathrm{R} \$ 0,35$ & 2640 & $\mathrm{R} \$ 924,00$ & 2640,00 \\
\hline $\begin{array}{c}\text { Camisa E Linha } \\
\text { Perdas Tecido }\end{array}$ & $\mathrm{Kg}$ & 0,324 & $\mathrm{R} \$ 8,75$ & 1320 & $\mathrm{R} \$ 11.547,36$ & 427,68 \\
\hline Tricoline & $\mathrm{Kg}$ & 0,028 & $\mathrm{R} \$ 0,76$ & 1320 & $\mathrm{R} \$ 1.000,69$ & 37,06 \\
\hline Botões & Unid. & 8 & $\mathrm{R} \$ 0,31$ & 1320 & $\mathrm{R} \$ 404,80$ & 10560,00 \\
\hline \multicolumn{5}{|c|}{ Sub Total Matéria Prima Mensal } & $\mathrm{R} \$ \mathbf{2 3 . 8 0 3 , 8 1}$ & 24689,49 \\
\hline
\end{tabular}

Fonte: Dados da pesquisa. 
Determinou-se o um estoque de segurança capaz de produzir 278 unidades, sendo 139 unidades para camisetas e 139 unidades para camisas, assim o montante do orçamento de matériaprima resultou no valor de $\mathrm{R}$ \$ 26.991,20, do qual estas informações possibilitaram fazer a menção aos custos fixos e variáveis operacionais totais para cada regime de tributação conforme apresentado na Tabela 9.

Tabela 9 - Custos fixos e variáveis operacionais

\begin{tabular}{cccc}
\hline Descrição dos Custos & Simples Nacional & Lucro Presumido & Lucro Real \\
\hline V. Total C. Fixos & $\mathrm{R} \$ 11.370,44$ & $\mathrm{R} \$ 13.658,09$ & $\mathrm{R} \$ 14.306,09$ \\
Total C. Variáveis & $\mathrm{R} \$ 29.130,06$ & $\mathrm{R} \$ 32.924,94$ & $\mathrm{R} \$ 33.848,60$ \\
\hline Total Geral & $\mathbf{R} \$ \mathbf{4 0 . 5 0 0 , 5 0}$ & $\mathbf{R} \$ \mathbf{4 6 . 5 8 3 , 0 2}$ & $\mathbf{R} \$ \mathbf{4 8 . 1 5 4 , 6 9}$
\end{tabular}

Fonte: Dados da pesquisa.

Avaliando a Tabela 9, observa-se o comportamento dos custos totais e nota-se que a diferença entre o simples nacional e o lucro presumido ficou em $\mathrm{R} \$ 6.082,52$ por mês, já em comparação entre o simples nacional e o lucro real a diferença alcançou o valor de $\mathrm{R} \$ 7.654,19$ ao mês. Na formação do preço de venda, um dos pontos primordiais para o sucesso de uma empresa, foram estabelecidos de acordo com a média de preço de $\mathrm{R} \$ 23,33$ premissa demonstrada pela pesquisa de mercado, que está apresentado na Tabela 10.

Tabela 10 - Preço de venda

\begin{tabular}{|c|c|c|c|c|c|c|c|c|c|c|}
\hline & \multicolumn{3}{|c|}{ Simples Nacional } & \multicolumn{3}{|c|}{ Lucro Presumido } & \multicolumn{3}{|c|}{ Lucro Real } & \multirow{2}{*}{$\begin{array}{c}\text { Ambos } \\
\text { Preço de } \\
\text { venda } \\
\end{array}$} \\
\hline Produto & Impostos \% & $\begin{array}{c}\text { Lucro } \\
\%\end{array}$ & $\begin{array}{l}\text { Mark-up } \\
\text { Multiplic }\end{array}$ & $\begin{array}{c}\text { Impostos } \\
\% \\
\end{array}$ & $\begin{array}{c}\text { Lucro } \\
\%\end{array}$ & $\begin{array}{l}\text { Mark-up } \\
\text { Multiplic }\end{array}$ & Impostos \% & $\begin{array}{c}\text { Lucro } \\
\%\end{array}$ & $\begin{array}{l}\text { Mark-up } \\
\text { Multiplic }\end{array}$ & \\
\hline $\begin{array}{c}\text { Camiseta } \\
\text { Masc. }\end{array}$ & 8,10 & 9,51 & 1,91 & 19,28 & 0,36 & 1,99 & 23,11 & 5,47 & 1,94 & $\mathrm{R} \$ 23,33$ \\
\hline $\begin{array}{c}\text { Camiseta } \\
\text { Fem. }\end{array}$ & 8,10 & 9,51 & 1,91 & 22,93 & 6,70 & 1,99 & 31,17 & 0,52 & 2,07 & $\mathrm{R} \$ 23,33$ \\
\hline Camisa & 8,10 & 9,00 & 1,59 & 19,28 & 1,62 & 1,69 & 21,63 & 9,28 & 1,69 & $\mathrm{R} \$ 23,33$ \\
\hline $\begin{array}{c}\text { Total } \\
\text { Médio }\end{array}$ & 8,10 & 6,01 & 1,80 & 20,50 & 6,23 & 1,89 & 25,30 & 1,76 & 1,90 & $\mathbf{R} \$ \mathbf{2 3}, \mathbf{3 3}$ \\
\hline
\end{tabular}

Fonte: Dados da pesquisa.

No cálculo do preço de venda pelo simples considerou-se a alíquota do imposto de $8,10 \%$, determinado pela provisão de que a receita bruta de vendas mensal seja de 61.602,06 que resulta na base de receita bruta anual de 739.224,67, enquadrada no Anexo II do regime simples nacional. Para o lucro presumido, os impostos incidentes foram de 1,20\% para o IRPJ, 1,08\% para a CSLL e 17\% para o ICMS. Já para as camisetas femininas além das alíquotas mencionadas para os demais produtos, incluem-se $0,65 \%$ para o PIS e 3,00\% para a COFINS.

Para a formação dos preços de venda e do mark-up pelo lucro real, considerou-se a incidência de ICMS $17 \%$ em todos os produtos e utilizou-se como base a percentagem de lucro líquido que se objetiva com a venda do produto para determinar a alíquota de 3,82\% direta do IRPJ 
sobre o preço de venda, resultante da alíquota de $15 \%$ multiplicada pelo lucro líquido estipulado de 28,04\%, o CSLL obteve a alíquota de 2,29\% direta sobre o preço de venda das camisetas masculinas, usado a mesma premissa de cálculo do IRPJ. O mesmo cálculo foi aplicado para as camisas, onde a alíquota direta do IRPJ foi de 2,89\% e a alíquota direta CSLL foi de 1,74\%, já para as camisetas femininas incide ainda o PIS com alíquota de 1,65\%, a COFINS com alíquota de 7,6\%, o IRPJ com alíquota de 3,08\% e a CSLL com alíquota de 1,85\% diretos sobre o preço de venda do produto.

Considerando-se a produção mensal de 1.320 camisetas e 1.320 camisas, que corresponde a $64,85 \%$ da demanda total de 4.071 unidades e considerando que todas essas unidades produzidas sejam vendidas, elaborou-se- DRE Projetada apresentada na Tabela 11.

Tabela 11 - DRE Projetada

\begin{tabular}{cccc}
\hline Regime de Tributação & Simples Nacional & Lucro Presumido & Lucro Real \\
\hline Receita bruta de vendas & $61.602,06$ & $61.596,61$ & $61.599,52$ \\
(-) Impostos & $4.989,77$ & $11.463,68$ & $12.985,85$ \\
= Receita Liquida & $56.612,29$ & $50.133,06$ & $48.613,13$ \\
(-) CPV & & & $6.100,39$ \\
Custos Fixos & $4.712,75$ & $6.100,39$ & $19.208,60$ \\
Custos Variáveis & $24.140,29$ & $20.056,84$ & $23.303,70$ \\
= Lucro bruto & $27.759,25$ & $23.976,42$ & $7.543,03$ \\
(-) Despesas Operacionais & $6.410,88$ & $7.310,88$ & 662,67 \\
(-) Despesas Financeiras média & 246,82 & 246,82 & $15.098,01$ \\
= Lucro antes IRPJ/CSLL & $21.101,55$ & $16.418,73$ & $1.033,85$ \\
(-) IRPJ & 0,00 & 739,17 & 620,31 \\
(-) CSLL & 0,00 & 665,25 & $\mathbf{R} \$ \mathbf{1 3 . 4 4 3 , 8 5}$ \\
\hline Lucro Líquido & $\mathbf{R} \mathbf{2 1 . 1 0 1 , 5 5}$ & $\mathbf{R \$ \mathbf { 1 5 . 0 1 4 , 3 1 }}$ \\
\hline
\end{tabular}

Fonte: Dados da pesquisa.

Com base na DRE pode-se determinar as margens de contribuição capaz de cobrir os custos fixos pelo simples nacional que ficou em $52,71 \%$, para o lucro presumido ficou em $46,55 \%$ e para o lucro real foi de $45,05 \%$. Quanto ao ponto do equilíbrio em valor contábil para o regime tributário do simples nacional foi de $\mathrm{R} \$ 21.570,67$, para o lucro presumido $\mathrm{R} \$ 29.341,87$ e para o lucro real $\mathrm{R} \$ 31.756,26$, que representam em relação a receita a porcentagem de $35,02 \%, 47,63 \%$ e $51,55 \%$ respectivamente. O ponto de equilíbrio unitário foi de 924 para o simples nacional, 1209 para o lucro presumido e 1374 para o lucro real. Na Tabela 12, é a presentado a Demonstração do Fluxo de Caixa projetado. 
Tabela 12 - Demonstração do fluxo de caixa projetado

\begin{tabular}{|c|c|c|c|c|c|c|}
\hline \multirow{2}{*}{$\frac{\text { Regime de Tributação }}{\text { Período }}$} & \multicolumn{2}{|c|}{ Simpl. Nacional } & \multicolumn{2}{|c|}{ Lucro Presumido } & \multicolumn{2}{|c|}{ Lucro Real } \\
\hline & $1^{o} M e \hat{s} R \$$ & $2^{o} M e \hat{s} R \$$ & $1^{o} M \hat{e}_{s} R \$$ & $2^{\circ}$ Mês $R \$$ & $1^{o} M e \hat{s} R \$$ & $2^{\circ} M \hat{e} s R \$$ \\
\hline Total das entradas & $97.504,20$ & $46.520,03$ & $97.504,20$ & $46.520,03$ & $97.504,20$ & $46.520,03$ \\
\hline Total das Saídas & $90.943,47$ & $39.309,28$ & $96.349,22$ & $45.256,88$ & $97.273,67$ & $46.181,33$ \\
\hline Saldo anterior & 0 & $6.560,73$ & 0 & $1.154,98$ & 0 & 230,53 \\
\hline Saldo do Mês & $6.560,73$ & $7.210,75$ & $1.154,98$ & $1.263,15$ & 230,53 & 338,7 \\
\hline Saldo Acumulado & $6.560,73$ & $13.771,48$ & $1.154,98$ & $2.418,13$ & 230,53 & 569,23 \\
\hline Período & $3^{\circ}$ Mês $R \$$ & $4^{o}$ Mês $R \$$ & $3^{\circ}$ Mês $R \$$ & $4^{o}$ Mês $R \$$ & $3^{\circ}$ Mês $R \$$ & $4^{\circ}$ Mês $R \$$ \\
\hline Total das entradas & $51.602,10$ & $59.909,92$ & $51.602,10$ & $59.909,92$ & $51.602,10$ & $59.909,92$ \\
\hline Total das Saídas & $39.309,28$ & $39.309,28$ & $45.256,88$ & $45.256,88$ & $46.181,33$ & $46.181,33$ \\
\hline Saldo anterior & $13.771,48$ & $26.064,30$ & $2.418,13$ & $8.763,35$ & 569,23 & $5.990,00$ \\
\hline Saldo do Mês & $12.292,82$ & $20.600,64$ & $6.345,22$ & $14.653,04$ & $5.420,77$ & $13.728,59$ \\
\hline Saldo Acumulado & $26.064,30$ & $46.664,94$ & $8.763,35$ & $23.416,39$ & $5.990,00$ & $19.718,58$ \\
\hline
\end{tabular}

Fonte: Dados da pesquisa.

Após a apresentação da projeção dos fluxos de caixa conforme as peculiaridades de cada regime tributário, são apresentados na Tabela 13 a projeção da análise financeira do projeto em questão.

Tabela 13 - Análise Financeira

\begin{tabular}{cccc}
\hline Resultados & Simples Nacional & Lucro Presumido & Lucro Real \\
\hline Payback & 6 Meses & 1 Ano & 1 Ano e 1 Mês \\
Tx de Atratividade & $10 \%$ & $10 \%$ & $10 \%$ \\
VPL em 5 Anos & $502.722,86$ & $221.454,90$ & $192.171,18$ \\
TIR em 5 Anos & $192,12 \%$, & $96,37 \%$ & $86,04 \%$. \\
\hline
\end{tabular}

Fonte: Dados da pesquisa.

De acordo com a Tabela 12, o maior fluxo de caixa é registrado pelo simples nacional ao longo do período de 4 meses. Com base nesses dados projetou-se o payback descontado para cada regime conforme a Tabela 13, onde o simples nacional aponta que a recuperação do investimento em aproximadamente 6 meses, pelo lucro presumido ocorre dentro do período de 1 ano e pelo lucro real é de 1 anos e 1 meses. Embora, os dados apontados na Tabela 13, não consideram que cerca de $62,30 \%$ do investimento trata-se de recursos vindos de financiamentos praticados em um período de 5 anos, cujo pressupõe-se que após o pagamento total deste investimento têm-se o período de retorno do investimento.

\section{Considerações Finais}

Para atingir o objetivo geral de analisar a viabilidade econômica e financeira para a implantação de uma indústria de confecções no município de Vista Gaúcha - RS, os dados apontam que aceitação do projeto ficou em $89 \%$ no segmento adulto com $71 \%$, considerando a produção de peças para o gênero feminino com $88 \%$, cuja demanda inicial apontada em unidades foi de 4.071, 
que representa $36,3 \%$ do mercado desta região. Bem como destacou-se que prezam por qualidade e o preço dos produtos, cujo este ficou na média de $\mathrm{R} \$ 23,34$.

Em relação a viabilidade econômico-financeira, por meio da projeção do preço de venda, dos custos, despesas e receitas, e dos instrumentos de análise financeira, para implantação do projeto o investimento inicial é de $\mathrm{R} \$ 79.578,00$, do qual $\mathrm{R} \$ 30.000,00$ será constituído de capital integralizado pelos sócios e o restante de $\mathrm{R} \$ 49.578,00$ foram simulados por meio das linhas de financiamento do FINAME e do PROGER. Observou-se que o melhor regime tributário para o projeto é o simples nacional, cuja margem de contribuição apurada foi de 52,71\%, o retorno do investimento no período de 6 meses e a TIR de 192,12\%, analisada sob a perspectiva de 5 anos de retorno do investimento.

Conclui-se que a implantação do projeto é viável, considerando as análises e mensurações realizadas ao decorrer do estudo nas demonstrações do resultado do exercício, fluxos de caixa, que possibilitaram aplicação das técnicas de cálculo do payback, do valor presente líquido e da taxa interna de retorno.

Recomenda-se para pesquisas futuras replicação deste estudo em outros municípios e regiões, também valendo ressaltar para desenvolver estudo de outros produtos voltados para a área de confecções de vestuário, ou mesmo para as outras linhas de produção, como exemplo de peças para cama, mesa e banho, ou para linha de confecções de roupas íntimas, dentre outras.

\begin{abstract}
The objective this research looks for analyses the economic and financial viability to implement a clothing industry in Vista Gaúcha - Rs municipality. As the methodology used, this study characterized as exploratory, quantitative and case study. The survey sample was added to 106 companies in the retail sale of clothing in the municipalities of Tres Passos - Rs, Tenente Portela Rs, Palmitinho - Rs and Vista Gaúcha - Rs. Thus, developed a market research took place in the northwest of Rio Grande do Sul, as well as a survey of budgets needed to projections of economic and financial statements and investment analysis tools was developed. The results of the study showed the feasibility of the project, considering the tax regimes of the country, which showed that the system is most advantageous economic and financially would be the tax regime of the national simple, how return on total investment of $\mathrm{R} \$ 79,578.00$ within 6 months after start of operations of the clothing industry.
\end{abstract}

Key-words:Business plan; Economic and financial viability; Investment projection.

\title{
Referências
}

ABIT - ASSOCIAÇÃO BRASILEIRA DA INDÚSTRIA TÊXTIL E DE CONFECÇÕES. Panorama do Setor Têxtil e de Confecções. 2011. Disponível em: 〈http://abit.org.br/abitonline/2011/06_07/apresentacao.pdf〉. Acesso em: 08 mai. 2013.

ABREU, M. M.; CARNEIRO, T. C. J. Análise comparativa de aplicação de metodologia de gerenciamento de projetos em uma grande empresa mineradora. Revista Gestão Industrial, v. 8, n. 3, 2012.

BACKER, M.; JACOBSEN, L. E. Contabilidade de Custos. São Paulo: Mc Graw-Hill do Brasil Ltda, 1977. 
BANCO DO BRASIL. PROGER Urbano Empresarial. 2013. Disponível em:

<http://www.bb.com.br/portalbb/page44,108,3221,8,0,1,2.bb>. Acesso em: 28 set. 2013.

BANCO NACIONAL DO DESENVOLVIMENTO ECONOMICO E SOCIAL. BNDES Finame. 2013. Disponível em:

<http://www.bndes.gov.br/SiteBNDES/bndes/bndes_pt/Institucional/Apoio_Financeiro/Produtos/FINAME_Maquinas e_Equipamentos/>. Acesso em: 28 set. 2013.

BARBETTA, P. A. Estatística aplicada as Ciências Sociais. 7. ed. Florianópolis: Ed. da UFSC, 2008.

BRAGA, R. Fundamentos e técnicas de administração financeira. 1. ed. São Paulo: Atlas, 2008.

BRASIL. Código Tributário Nacional, Constituição Federal, Legislação Tributária. 17. ed. São Paulo: Editora Revista dos Tribunais, 2012.

Decreto n 3.000, de 26 de março de 1999. Presidência da República. Casa Civil. Regulamenta a tributação, fiscalização, arrecadação e administração do Imposto sobre a Renda e Proventos de Qualquer Natureza. Disponível em: <http://www.planalto.gov.br/ccivil_03/decreto/d3000.htm>. Acesso em: 20 abr. 2013.

Lei Complementar $\mathbf{n}^{0}$ 123, de 14 de Dezembro de 2006. Presidência da República. Casa Civil. Subchefia para Assuntos Jurídicos. Institui o Estatuto Nacional da Microempresa e da Empresa de Pequeno Porte; altera outros dispositivos. Disponível em: <http://www.planalto.gov.br/ccivil_03/leis/lcp/lcp123.htm>. Acesso em: 20 abr. 2013.

Lei $\mathbf{n}^{\mathbf{0}}$ 12.814, de 16 de Maio de 2013. Presidência da República. Casa Civil. Subchefia para Assuntos Jurídicos. Altera a Lei $\mathrm{n}^{\mathrm{0}}$ 12.096, de 24 de novembro de 2009; altera a Lei $\mathrm{n}^{\mathrm{0}}$ 11.529, de 22 de outubro de 2007; altera a Lei $\mathrm{n}^{\mathrm{o}}$ 12.409, de 25 de maio de 2011; altera as Leis $\mathrm{n}^{\mathrm{os}} 12.487$, de 15 de setembro de $2011,9.718$, de 27 de novembro de 1998, e 11.491, de 20 de julho de 2007; prorroga os prazos previstos nas Leis $\mathrm{n}^{\text {os }} 12.249$, de 11 de junho de 2010 , e 11.941, de 27 de maio de 2009. Disponível em: 〈http://www.planalto.gov.br/ccivil_03/_Ato20112014/2013/Lei/L12814.htm>. Acesso em: 20 abr. 2013.

BRUNI, A. L.; FAMÁ, R. As decisões de investimento. 2. ed. São Paulo: Atlas, 2007.

CERVO, A. L.; BERVIAN, P. A. Metodologia científica. 4. ed. São Paulo: Makron Books, 1996.

CORONETTI, J.; BEUREN, I. M.; SOUSA, M. A. B.. Os métodos de custeio utilizado nas maiores indústrias de Santa Catarina. Revista Eletrônica de Gestão Organizacional, v. 10, n. 2, 2012.

CREPALDI, S. A. Curso básico de contabilidade de custos. São Paulo: Atlas, 1999.

FABRETTI, L. C. Contabilidade tributária. 9. ed. São Paulo: Atlas, 2005.

FUNDAÇÃO GETULIO VARGAS. Custo de capital para geração de energia hídrica no Brasil por meio de pequenas centrais hidrelétricas (PCHS) e usina hidrelétrica de energia (UHE) até 50 MW no contexto do mecanismo de desenvolvimento limpo. 2010. Disponível em: <http://www.abce.org.br/downloads/portugueswacc.pdf>. Acesso em: 21 mai. 2013.

FUNDAÇÃO INSTITUTO DE PESQUISAS ECONOMICAS. Preços Médio de Veículos e Passeio/Utilitários. 2013. Disponível em: <http://www.fipe.org.br/web/index.asp?aspx=/web/indices/veiculos/introducao.aspx >. Acesso em: 28 set. 2013.

GIL, A. C. Métodos e técnicas de pesquisa social. 5. ed. São Paulo: Atlas, 1999.

GRAY, J.; JOHNSTON, K. S. Contabilidade e Administração. São Paulo: Editora McGraw-Hill do Brasil Ltda, 1977.

INFOMONEY. PIB: entenda quais são os fatores que influenciam o crescimento da economia. 2007. Disponível em: <http://www.infomoney.com.br/ultimas-noticias/noticia/257984/pib-entenda-quais-sao-fatores-que-influenciamcrescimento-economia>. Acesso em: 21 mai. 2013.

IBAPE - SP. Estudo de vida úteis para máquinas e equipamentos. Disponível em: < http://www.ibapesp.org.br/arquivos/ESTUDO_DE_VIDAS_UTEIS.apresentacao.pdf>. Acesso em: 14 set. 2013.

IUDÍCIBUS, S. Contabilidade Gerencial. 6. ed. São Paulo: Atlas, 1998. 
LEITE, H. P. Introdução a administração financeira. 2. ed. São Paulo: Atlas, 1994.

LEONE, G. S. G. Custos: planejamento, implantação e controle. 3. ed. São Paulo: Atlas, 2009.

MARTINS, E. Contabilidade de custos. 7. ed. São Paulo: Atlas, 2000.

OLIVEIRA, L. M., CHIEREGATO, R., PEREZ, J. H. JR. \& GOMES, M. B. Manual de contabilidade tributária. 3. ed. São Paulo: Atlas, 2004.

PADOVEZE, C. L. Contabilidade gerencial: um enfoque em sistema de informação contábil. 5. ed. São Paulo: Atlas, 2009.

PINTO, A. A. G.,LIMEIRA, A. L., SILVA, C. A. S. \& COELHO, F. S. Gestão de custos. 2. ed. Rio de Janeiro: Editora FGV, 2008.

RECEITA FEDERAL DO BRASIL. Instrução Normativa SRF no 162/1998. Disponível em:

<http://www.receita.fazenda.gov.br/Legislacao/ins/Ant2001/1998/in16298ane1.htm>. Acesso em: 28 set. 2013.

. Taxa de Juros à Longo Prazo. 2013. Disponível em:

<http://www.receita.fazenda.gov.br/pessoajuridica/refis/tjlp.htm>. Acesso em: 28 set. 2013.

SANTOS, J. J. Análise de custos: remodelado com ênfase para sistema de custeio marginal, relatórios e estudos de casos. 4. ed. São Paulo: Atlas, 2005.

SEBRAE. Fatores Condicionantes e Taxa de Mortalidade de Empresas no Brasil. Brasília: Sebrae, 2004.

Disponível em:

<http://www.biblioteca.sebrae.com.br/bds/BDS.nsf/9A2916A2D7D88C4D03256EEE00489AB1/\$File/NT0008E4CA.p df>. Acesso em: 21 mai. 2013.

Taxa de Sobrevivência das Empresas no Brasil. 2011. Disponível em:

<http://www.biblioteca.sebrae.com.br/bds/BDS.nsf/45465B1C66A6772D832579300051816C/\$File/NT00046582.pdf〉. Acesso em: 21 mai. 2013.

SEVERIANO FILHO, C.; MELO, J. F. M. Desmistificando as limitações do uso do custeio por absorção.Contabilidade Vista \& Revista, v. 17, n. 3, p. 11-24, 2009.

SEVERINO, A. J. Metodologia do trabalho científico. 23. ed. São Paulo: Cortez, 2007.

SIVERGS. Contribuição Sindical - Tabela 2014. 2013. Disponível em:

<http://sindical.sistemaindustria.org.br/SEGR8GRCSUp003.ASP?NumAno=\%220\%22>. Acesso em: 19 out. 2013.

Convenção Coletiva de Trabalho 2013/2014. 2013. Disponível em: 〈http://www.stivestuario-poa.org.br/>. Acesso em: 12 out. 2013.

ZDANOWICZ, J. E. Planejamento Financeiro e Orçamento. 4. ed. Porto Alegre: Editora Sagra Luzzatto, 2001.

\section{Dados da autora:}

\section{Nome: Camila Freitas Sant'Ana}

Filiação Institucional: Universidade Regional de Blumenau

Departamento: Ciências Contábeis

Função ou cargo ocupado: Mestranda

Endereço completo para correspondência: Rua Antônio da Veiga, 140 - Victor Konder -

Blumenau/SC - Brasil - CEP: 89012-900.

Telefones para contato: (47) 3321-0565 / (47) 9254-1800 
e-mail:camila-fsantana@hotmail.com / mila-internacional@hotmail.com

Submetido em: 2014-12-20

Aceito em: 2015-05-07 